\title{
LA CONSTRUCCIÓN DE UNA INSTITUCIÓN COMERCIAL: EL CONSULADO DE LAS NACIONES FLAMENCA Y ALEMANA EN LA SEVILLA MODERNA ${ }^{1}$
}

\author{
José Manuel Díaz Blanco \\ Universidad de Huelva
}

Fecha de recepción: enero 2015

Fecha de aceptación: mayo 2015

Este trabajo pretende adentrarse en la historia de una institución vinculada al comercio de Sevilla durante la Edad Moderna: el consulado de las naciones flamenca y alemana ${ }^{2}$. Los comerciantes extranjeros en la capital andaluza y los flamencos-alemanes en particular han sido objeto de una atención historiográfica satisfactoria, pero

1. Este trabajo se ha realizado gracias al programa Juan de la Cierva, del Ministerio de Economía y Competitividad de España, exp. JCI-2011-11153, adscrito a la Universidad de Huelva.

2. La bibliografía sobre el consulado flamenco-alemán es muy escasa, incluyendo la relativa a la capilla y el hospital de los que surgió: BLondÉ, Anne: Ontstaan en ontwikkeling van de functie van consul van de (Zuid-)Nederlandse handelsnaties in Spanje tijdens de 16de en 17de eeuw, Gante, tesis de máster del curso 2008-2009 y Gamero RoJas, Mercedes: «Flamencos en la Sevilla del siglo XVII: la capilla y el hospital de San Andrés», en prensa, y tienen también noticias de gran interés Hoys, Hye: Fondations pieuses et charitables des marchands flamands en Espagne, Bruselas, 1882 (ed. facsímil: Fundación Carlos de Amberes), pp. 19-38; Concha, Ignacio de la: «El Almirantazgo de Sevilla. Notas para el estudio de las instituciones mercantiles en la Edad Moderna», Anuario de Historia del Derecho Español, 19 (1948), pp. 459-525; García GarCíA, Bernardo J: «La Nación Flamenca en la corte española y el Real Hospital de San Andrés ante la crisis sucesoria (1606-1706)», en Álvarez-Ossorio, Antonio, García Bernardo J. y León, Virginia (coords.), La pérdida de Europa. La guerra de Sucesión por la Monarquía de España, Madrid, 2007, pp. 379-442. En todo caso, la separación entre nación, comunidad e instituciones no es tajante en ninguno de estos trabajos ni en los que se citan en la nota siguiente, así como en CRESPO Solana, Ana (coord.): Comunidades transnacionales. Colonias de mercaderes extranjeros en el Mundo Atlántico (1500-1830), Madrid, Doce Calles, 2010; Crespo Solana, Ana y Montojo Montojo, Vicente: «La Junta de Dependencia de Extranjeros (1714-1800): Trasfondo socio-político de una historia institucional», Hispania, 232 (2009), pp. 363-394, en que se presta una atención detallada a los conceptos de nación y comunidad, y la relación con el plano institucional. 
desde un punto de vista esencialmente socio-económico ${ }^{3}$. La historia institucional y política se ha cultivado con menor entusiasmo y el caso que ocupa las presentes páginas se halla agravado por diversos factores técnicos y conceptuales. El primero de ellos es la ausencia de un archivo propio, cuya consulta facilite el proceso de investigación. El consulado flamenco-alemán dispuso de uno, pero parece perdido ${ }^{4}$. De tal modo, hay que reconstruir su documentación, inevitablemente de forma parcial, a través del rastreo entre los protocolos notariales. A diferencia del Consulado de Cargadores o la Casa de la Contratación, el consulado flamenco-alemán careció de un escribano propio y tuvo que garantizar la fe pública de sus documentos a través de los escribanos del número ${ }^{5}$. Perdidos los ejemplares del propio consulado, sobreviven los de ellos, afortunadamente en abundancia ${ }^{6}$.

Otro factor que ha condicionado la investigación sobre el consulado flamenco-alemán reside en su ambigua vinculación con la Carrera de Indias. El estudio del comercio sevillano ha tendido a privilegiar la vertiente colonial de éste, en detrimento de la aten-

3. Domínguez Ortiz, Antonio: Los extranjeros en la vida española del siglo XVII y otros artículos, Sevilla, 1996; Moret, Michèle: Aspects de la Société Marchande de Séville au début du XVIIe siècle, París, 1967; Stols, Eddy: «La colonia flamenca de Sevilla y el comercio de los Países Bajos en la primera mitad del siglo XVII», Anuario de Historia Económica y Social, 2 (1969), pp. 363-381 y De Spaanse Brabanders of de Handelsbetrekkingen der Zuidelijke Nederlanden met de Iberische Wereld 1598-1648, Bruselas, 1971; Berthe, Jean Pierre: «Les Flamands à Séville au XVI ${ }^{\mathrm{e}}$ siècle», en Kellenbenz, Hermann (ed.), Kölner Kolloquien zur internationalen Sozial-und Wirtschaftsgeschichte, t. 1: Fremde Kaufleute auf der iberischen Halbinsel, Colonia-Viena, 1970, pp. 239-251; ABADÍA Flores, Carolina: Los flamencos en Sevilla en los siglos XVI-XVII, Gante, curso 2006-2007, disponible en: http://lib.ugent.be/fulltxt/ RUG01/001/309/918/RUG01-001309918_2010_0001_AC.pdf [consultado 26/12/2014); CraILSHEIM, Eberhard: «Behind the Atlantic Expansion: Flemish Trade Connections of Seville in 1620», Research in Maritime History, 43 (2010), pp. 21-46 y «Extranjeros entre dos mundos: una aproximación proporcional a las colonias de mercaderes extranjeros en Sevilla, 1570-1650», Jahrbuch für Geschichte Lateinamerikas/ Anuario de Historia de América Latina, 48 (2011), pp. 179-202. Además de las comunidades mercantiles, también han recibido una gran atención los artistas, especialmente Cornelio Schut y José de Arce, que cuentan con nutridas bibliografías propias.

4. Domínguez Ortiz, Antonio: «Documentos sobre los mercaderes flamencos establecidos en Sevilla a comienzos del siglo XVIII», en En torno al municipio en la Edad Moderna, Granada, 2006, pp. 397-415, especialmente p. 403.

5. En todo caso, también instituciones como el Consulado o la Casa tuvieron que protocolizar ante los escribanos del número. Los filones documentales de ambas instituciones en los archivos notariales de Sevilla son de una enorme riqueza y, en el futuro, deberían estudiarse como complemento a los fondos conservados en el Archivo de Indias.

6. Archivo Histórico Provincial de Sevilla, Protocolos Notariales de Sevilla (AHPSe, PNS), donde los oficios 16 y 19 se destacan como las series más abundantes desde la perspectiva institucional. Las fuentes notariales se han enriquecido con los de otros archivos locales y el Archivo General de Indias. En el futuro será necesario investigar también en el Archivo General de Simancas, especialmente en las secciones de Estado, Cámara de Castilla y Secretarías provinciales (Consejo Supremo de Flandes y Borgoña). Agradezco a Bernardo J. García García que me informase sobre estas posibilidades de investigación en Simancas, así como muchos otros buenos consejos sobre la materia. 
ción que debería merecer su profunda integración en la economía mercantil europea ${ }^{7}$. Esto es cierto en los ámbitos social y económico y vuelve a serlo en el político. Dentro de la limitada atención a los aspectos institucionales, se conocen relativamente bien organismos como el Consejo de Indias, la Casa de la Contratación o el Consulado de Cargadores, a pesar de que en muchos casos se echen de menos estudios monográficos sobre ellos que aún no se han emprendido ${ }^{8}$; en cambio, se ha indagado mucho menos en la implicación del Cabildo en la vida del comercio, o en la existencia de otras instituciones que no pertenecían directamente a la estructura del Monopolio indiano, como los consulados de extranjeros o los jueces conservadores, más emparentados con la organización comunitaria de las «naciones» extranjeras presentes en la ciudad. Es cierto que éstos disfrutaron de un protagonismo limitado durante los años de esplendor del sistema monopolístico, pero a lo largo del siglo XVII fueron cobrando cada vez más un firme vigor ${ }^{9}$. Un capítulo esencial de ese proceso, acaso el más destacado, lo escribió el consulado de las naciones flamenca y alemana.

$\mathrm{Su}$ perfil es el de una institución cuidadosamente regulada, a través de la cual se expresaban sectores importantes de la sociedad hispalense del siglo XVII, fundamentalmente grandes comerciantes flamencos y alemanes que actuaban en las rutas mercantiles que unían Andalucía con el norte de Europa y la América virreinal. Sobre el telón de fondo de la expansión internacional flamenca y el cosmopolitismo de las comunidades y redes mercantiles europeas ${ }^{10}$, su motor fue la tensión de la vida institucional del comercio: surgió como mecanismo de defensa ante la agresividad exclu-

7. Gamero RoJas, Mercedes: «El comercio entre Sevilla y el norte de Europa en el siglo XVIII», en Estudios de Historia Moderna en homenaje al profesor Antonio García-Baquero, Sevilla, 2009, pp. 337-347.

8. García-BAQUERO González, Antonio: La Carrera de Indias: suma de la contratación y océano de negocios, Sevilla, 1992; Crespo Solana, Ana: La Casa de la Contratación y la Intendencia General de la Marina en Cádiz, 1717-1730, Cádiz, 1996; CARLos Boutet, Guiomar de (coord.): España y América: un océano de negocios, Madrid, 2003; VILA, Enriqueta, Acosta, Antonio y GonzÁLEZ, Adolfo (coords.): La Casa de la Contratación y la navegación entre España y las Indias, Sevilla, 2004; BERNAL RodríGueZ, Antonio M: España, proyecto inacabado. Costes/beneficios del Imperio, Madrid, 2005; Díaz Blanco, José Manuel: Así trocaste tu gloria. Guerra y comercio colonial en la España del siglo XVII, Madrid, 2012.

9. Aglietti, Marcella, Herrero, Manuel y Zamora, Francisco (coords.): Los cónsules de extranjeros en la Edad Moderna y a principios de la Edad Contemporánea, Madrid, 2013; García Bernal, Jaime y Gamero Rojas, Mercedes: «Las corporaciones de nación en la Sevilla moderna: fundaciones, redes asistenciales y modelos de sociabilidad», en GARCíA y ReCIO: Las corporaciones de nación, pp. 347-387.

10. Para la expansión flamenca por Europa y otros continentes, BRULEz, Wilfrid: De firma Della Faille en de internationale handel van Vlaamse firma's in de 16 e eeuw, Bruselas, $1959 \mathrm{y}$ «De diaspora der Antwerpse kooplui op het einde van de 16e eeuw», Bijdragen voor de Geschiedenis der Nederlanden, 15 (1960), pp. 229-306; VAN DeR WeE, Herman: The growth of the Antwerp market and the European economy, La Haya, 1963; BAETEns, Roland: De nazomer van Antwerpens welvaart: De diaspora en het handelshuis De Groote tijdens de eerste helft der XVIIe eeuw, Bruselas, 1976; Crespo SolAnA, Ana: Mercaderes atlánticos. Redes del comercio flamenco y holandés entre Europa y el Caribe, Córdoba, Universidad, 2009, «Elementos de transnacionalidad en el comercio flamenco-holandés en Europa y la Monarquía Hispánica», Cuadernos de Historia Moderna. Anejos, 10 (2011), pp. 55-76. García, Bernardo y ReCio, Óscar (eds.), Las corporaciones de nación en la Monarquía Hispánica (1580-1750). Identidad, patro- 
sivista del Consulado de Cargadores a Indias y contó con el apoyo de la Corona, que no quería enajenarse el favor de unos vasallos y colaboradores tan valiosos, sino más bien incentivar su actividad. Llegó a erigirse en una institución importante del mundo comercial sevillano, cuyas vicisitudes históricas pueden reconstruirse con coherencia:

1. Segunda mitad del siglo XVI-comienzos del XVII: Primeras noticias sobre la existencia de cónsules flamencos, ajenos a la mecánica definitiva del consulado flamenco-alemán.

2. 1602-1615: Establecimiento de la capilla y el hospital de San Andrés. Se trataba de un par de instituciones piadosas, que fueron el germen del consulado flamenco-alemán.

3. 1615-1625: Período fundamental en el que se efectuó la transición de la capilla al consulado, convirtiendo a los mayordomos viejos en los nuevos cónsules.

4. Reinado de Felipe IV: Etapa de consolidación de la nueva institución. Durante la privanza de Olivares, el favor que le dispensó la cúpula del poder la protegió de la hostilidad del Consulado de Cargadores; tras la caída del privado, experimentó algunas dificultades, pero pudo superarlas.

5. Reinado de Carlos II: El consulado flamenco-alemán vivió el momento de su mayor influencia política, ante la amenaza comercial que Cádiz significaba para Sevilla.

No hay espacio en estas páginas para extender el análisis al siglo XVIII ${ }^{11}$. Por eso, se detendrá conscientemente en la frontera del 1700, que a veces es una frontera imaginaria, pero que en otras ocasiones es una frontera real. Éste es uno de esos casos. El cambio dinástico, el nuevo mapa europeo surgido de Utrecht y Rastadt, la modifi-

nazgo y redes de sociabilidad, Madrid, 2014, ofrece una visión de contexto, al tratar simultáneamente la implantación de comunidades extranjeras en el conjunto de la Monarquía Hispánica.

En Castilla: para Madrid, Vidal Galache, Florentina y Benicia: Fundación Carlos de Amberes. Historia del Hospital de San Andrés de los Flamencos, 1594-1994, Madrid, 1996; García García, Bernardo J: «La Real Diputación de San Andrés de los Flamencos. Formas de patronazgo e identidad en el siglo XVII», en GARCíA y Recio (eds.): Las corporaciones, pp. 59-107; para Cádiz, confundiéndose con la población neerlandesa, Bustos Rodríguez, Manuel: «Le consulat des Flamands à Cádiz après la Paix d'Utrecht (1713-1730): Jacques Vermolen», Parmentier, Jan y Spanoghe, Sander (eds.): Orbis in Orbem. Liber Amicorum John Everaert, Gante, 2001, pp. 108-132; Crespo Solana, Ana: Entre Cádiz y los Países Bajos. Una comunidad mercantil en la ciudad de la ilustración, Cádiz, Ayuntamiento, 2001.

11. Sobre los flamencos de Sevilla en el siglo XVIII, Gamero Rojas, Mercedes y Fernández Chaves, Manuel F., entre cuyos trabajos: «Flamencos en la Sevilla del siglo XVIII: entre el norte de Europa y América», en Navarro Antolín, Fernando (coord.), Orbis Incognitus: avisos y legajos del Nuevo Mundo, Huelva, 2009, vol. II, pp. 211-220; «Flamencos en la Sevilla del siglo XVIII: las estrategias familiares, redes clientelares y comportamientos económicos», en Bravo CARO, Juan Jesús y SANZ Sampelayo, Luis (coords.), Población y grupos sociales en el Antiguo Régimen, Málaga, 2009, pp. 571586. En el siglo XVIII se acentuó la relación (llegando a ser de dependencia) con la comunidad gaditana, generalizándose la expresión «Muy Antigua y Noble Nación Flamenca de Sevilla y Cádiz: CRESPO Solana: Entre Cádiz y los Países Bajos, p. 133. 
cación en la vinculación política de los flamencos con la Corona de España y la basculación hacia Cádiz del comercio colonial, con el importante hito de 1717, abrieron un tiempo histórico bastante diferente para el consulado flamenco-alemán. Sin duda, el esplendor que disfrutó a fines del XVII terminó y se observa que sus propias mecánicas institucionales tendieron a cambiar ${ }^{12}$. El proceso, evidentemente, es demasiado complejo para resumirse en unas breves líneas últimas.

\section{LA CAPILLA Y EL HOSPITAL DE SAN ANDRÉS}

A lo largo del siglo XVI, Sevilla se convirtió en una de las grandes plazas del comercio internacional, inserta dentro de las principales rutas mercantiles europeas y situada en una posición privilegiada del sistema de monopolio de la Carrera de Indias ${ }^{13}$. El carácter transnacional de este sector económico generó comunidades cosmopolitas allí donde floreció. Sevilla no fue una excepción y se pobló de extranjeros a lo largo del XVI. Entre ellos tuvieron gran importancia numérica y cualitativa los oriundos de los Países Bajos, cuya cúspide estuvo formada por una élite dedicada lucrativamente a los negocios. Los mercaderes flamencos formaron parte del dinamismo comercial hispalense en su siglo de oro y de plata.

Entrado el siglo XVII, la comunidad flamenca comenzó a organizarse institucionalmente ${ }^{14}$. En primer lugar, hizo lo más sencillo: crear una capilla y un hospital. Los orígenes de esta fundación piadosa pueden narrarse con minuciosidad gracias a sus constituciones y estatutos, fechados en $1615^{15}$. Se remontan a 1602, cuando se fundó el hospital, que ocupaba una casa en la plazuela de Santo Tomás, frontera al colegio dominico de Santo Tomás de Aquino ${ }^{16}$. Dos años después, en 1604, surgió la idea de

12. Por ejemplo, los cónsules alemanes dejaron de nombrase en las mismas elecciones que los cónsules flamencos, aunque durante algún tiempo siguiesen sirviendo como tales: AHPSe, PNS, legs. 10.324, fol. 116; 10.328, fol. 254. Antonio María de Espinosa dice en su edición de la obra histórica de Ortiz de Zúñiga de finales del XVIII: «Se conserva la capilla y Hospital [de los flamencos] muy olvidado, y sin la opulencia que adquirió en estos años [hacia 1625]: cuya noticia no hemos querido omitir por ser una de las cosas que demuestra la grandeza á que llegó el comercio de esta Ciudad», en ORTIZ DE ZúÑIGA, Diego: Anales eclesiásticos y seculares de la muy noble y muy leal ciudad de Sevilla, Madrid, 1796 [1677], IV, p. 444.

13. Domínguez Ortiz, Antonio: Orto y ocaso de Sevilla, Sevilla, 1991; Morales Padrón, Francisco: La ciudad del Quinientos, Sevilla, 1977.

14. Es necesario considerar la posibilidad de modelos organizativos en el XVI. Como se verá más adelante, hay noticias fiables sobre el consulado, pero no sobre capillas y hospitales, salvo algunas referencias breves de la segunda mitad del XVII, en los Anales de Ortiz de Zúñiga o en los memoriales del propio consulado. Aunque estas últimas no puedan documentarse de forma directa, la existencia de antecedentes de la capilla en el XVI no puede descartarse y debe tenerse presente.

15. AHPSe, PNS, leg. 12.713, fols. 435-447; fundación de estatutos, Sevilla, 17 de julio de 1615. Desde ahora se citará como Estatutos.

16. Archivo de la Parroquia del Sagrario, Padrones, lib. 1 (y sucesivos), donde aparece mencionado como «hospital de los flamencos». Para seguir la pista de este inmueble: AHPSe, PNS, leg. 12.920, fol. 121. 
la capilla, que debió de hacerse realidad materialmente hacia $1607^{17}$. Situada en el claustro del colegio de Santo Tomás, muy cerca por tanto del hospital, nació con el fin de que los flamencos tuviesen un lugar donde adorar colectivamente a Dios. Allí, ante el Martirio de San Andrés de Juan de Roelas, que decoraba el altar mayor, elevaron sus oraciones y colocaron sus sepulcros familiares algunos de los más acaudalados miembros de la comunidad ${ }^{18}$.

La consolidación del hospital y la casa pía vino gracias a la consecución de medios económicos que posibilitaron su sostenimiento material. Las vías de ingreso originales consistieron en figuras impositivas que, mediante la aprobación de Felipe III, gravaron la actividad comercial de los flamencos. Una primera cédula, firmada en Valladolid en 1604, estableció que deberían pagarse a la capilla el 0'1\% del valor de las mercancías que los flamencos pasasen por la Aduana, tanto de entrada como de salida, así como una tasa fija de ocho maravedís por cada tonelada que pesasen. Esta disposición, que inicialmente fue coyuntural, se perpetuó en 1607 a través de una segunda cédula y, finalmente, se amplió. Cada vez se atendía a más compatriotas y durante aquellos años iniciales los gastos habían sido bastante altos. Pese a los buenos ingresos que habían reportado los primeros ingresos, la capilla y el hospital acumularon una deuda de 7.000 ducados, por lo que en 1611 se decidió incrementar la contribución a un $0^{\prime} 2 \%{ }^{19}$. El Rey confirmó el cambio a fines de 1614, cuando ya debían de sentirse sus efectos benéficos; asegurada la viabilidad económica de la institución, se procedió a dotarle pocos meses después de una normativa que fijase su funcionamiento a largo plazo ${ }^{20}$.

17. Esta datación es posible a través de los protocolos notariales, que registran en 1607 y 1608 las primeras adjudicaciones de sepulturas y capillas, así como el primer poder de administrador para fray Enrique Conde y los primeros nombramientos de diputados, luego mayordomos: AHPSe, PNS, legs. 12.648, fol. $154 ; 12.649$, fol. $91 ; 12.654$, fol. $249 ; 12.657$, fols. 847 y 851 . En todo caso, hay noticias de que antes de instalarse en Santo Tomás, los flamencos contaban con un pequeño espacio en la parroquia de San Martín: Archivo Municipal de Sevilla (AMS), secc. XI, t. 13, n. 5.

18. Además de la documentación citada en la nota anterior, véase también AHPSe, PNS, legs. 12.822, fol. 987; 12.845, fol. 817. Sobre el colegio, véase GóngorA, Diego Ignacio de: Historia del Colegio Mayor de Santo Tomás de Sevilla, Sevilla, 1890.

19. Evidentemente, la construcción de este sistema fiscal propio hizo depender menos a la capilla de las donaciones privadas y las limosnas, que lógicamente también existieron y fueron importantes. GARCía Bernal y Gamero Rojas: «Las corporaciones de nación», p. 363, presentan las relaciones porcentuales entre estos tipos de ingresos y puede observarse una estructura de ingresos diferente al cercano Patronato flamenco en Cádiz: Crespo Solana, Ana: «El Patronato de la nación flamenca gaditana en los siglos XVII y XVIII: trasfondo social y económico de una institución piadosa», Studia Historica. Historia Moderna, 24 (2002), pp. 297-329 y «Nación extranjera y cofradía de mercaderes: el rostro piadoso de la integración social», en VILlaR, Begoña y PEzzI, Pilar (coords.): Los extranjeros en la España Moderna, Málaga, Universidad, 2003, II, pp. 175-188.

20. Estatutos, fols. 437-438 y 439-440; reales cédulas, Valladolid, 8 de abril de 1604, Madrid, 25 de enero de 1607 y San Lorenzo de El Escorial, 2 de octubre de 1614. Están transcritas íntegramente en el documento. También se resumen en AMS, secc. XI, t. 13, n. 3; que incorpora además otra de 20 de abril de 1667 , por la que se aumentaban las limosnas. Responde a una decisión tomada en 1665, a causa de la mala situación económica de la capilla y sus obras: AHPSe, PNS, leg. 12.972, fols. 222-223. 
Una junta de gobierno bien estructurada dirigía la capilla. Los estatutos señalan varias figuras, entre las que cabe destacar el administrador, el tesorero y los cuatro mayordomos ${ }^{21}$. El administrador era un religioso, o lo fue durante la mayor parte del siglo XVII, aunque sus funciones no se limitaban a la dirección espiritual de la comunidad, sino que comprendían también lo económico, lo jurídico y lo administrativo $^{22}$. Aunque se deliberaba su titularidad durante cada proceso electoral, lo cierto es que la tendencia general se inclinaba a renovarlos de forma casi automática, de modo que se convirtieron en figuras que aseguraban una cierta estabilidad y coherencia a largo plazo al gobierno de la capilla, en contraste con la continua renovación de los demás cargos. El primer administrador, fray Enrique Conde, OP, llegó a convertirse en administrador perpetuo excepcionalmente, a causa del especial carisma del personaje, líder visible de la comunidad flamenca hispalense a fines del XVI y durante el primer cuarto del XVII ${ }^{23}$. Después de él, otros dominicos flamencos como fray Fernando de Rebolledo, fray Domingo de Bruselas o fray Juan Bautista Pluyms ocuparon la administración durante períodos bastante prolongados, en ocasiones de más de veinte años consecutivos $^{24}$.

Puramente económico fue el puesto de tesorero, que empeñaba a su titular en el manejo de los caudales de la capilla y el hospital. El tesorero recibía la recaudación de los impuestos aduaneros y se encargaba de efectuar los pagos, pero nunca siguiendo un criterio propio, sino atendiendo a las órdenes que le hacían llegar el administrador y los mayordomos ${ }^{25}$. Con todo, era un puesto de la mayor responsabilidad y confianza, así que con bastante frecuencia se confiaba una mayordomía a los que lo desempeñaban poco después de que terminasen su ejercicio. Los cuatro mayordomos eran el alma de la capilla y, según se verá más adelante, el germen del consulado flamenco-alemán. Tenían la máxima capacidad de gobierno, lo que significaba tomar decisiones sobre los problemas que afectaban a la capilla y al hospital durante el día a día, que, según puede suponerse, eran de índole económica en su gran mayoría. Había cuatro mayordomos, aunque -aspecto esencial, como se verá más adelante- se distinguían dos mayordomos nuevos y dos antiguos. Los nuevos eran los que se nombraban directamente durante cada proceso electivo y los antiguos, los que habían sido seleccionados la vez ante-

21. Estatutos, fol. 441. Se les reconoce un «absoluto poder para el gobierno de los dichos lugares, capilla y casa pía».

22. Ibid., fol. 442 .

23. Ibid., fols. 442v-443r. Algunos nombramientos y encargos en AHPSe, PNS, legs. 12.635, fol. 1.178; 12.640, fol. 226; 12.651, fol. 264; 10.028, fol. 1; 12.691, fol. 1.152; ó 12.697, fol. 923. El prestigio del P. Conde era de tal calibre que incluso la nación francesa le extendió poderes cuando intentó renovar su sistema de representación consular: AHPSe, PNS, leg. 12.738, fol. 587.

24. No siempre ha sido posible encontrar los procesos electivos de los administradores, que se desarrollaban con frecuencia al margen de las elecciones principales de los demás cargos y seguían una mecánica diferente: eran los comerciantes quienes proponían la terna y los cargos de gobierno quienes elegían al titular: AHPSe, PNS, legs. 12.785, fol. 10; 12.892, fol. 850; 13.018, fols. 606 y 653.

25. Estatutos, fol. 442. 
rior $^{26}$. Estas mayordomías, a causa de la preeminencia que se les reconoció, tendieron a ser ocupadas por los más afamados hombres de negocios flamencos que había en Sevilla. Nada de lo que extrañarse: los comerciantes eran la élite social de la comunidad $\mathrm{y}$, al fin y al cabo, eran quienes pagaban con su actividad los recursos económicos que gestionaban los mayordomos.

Desde 1616, después de la aprobación de los estatutos, las elecciones empezaron a celebrarse bienalmente ${ }^{27}$. Tenían lugar en la propia capilla de San Andrés y, si ninguna incidencia modificaba la planificación normal, en ellas se escogía o renovaba al administrador, se elegía al tesorero y los dos mayordomos nuevos, y se confirmaba a los mayordomos antiguos. El gobierno saliente tenía el derecho de proponer a los candidatos, generalmente por ternas; junto a los cargos que repetían, era una forma de conseguir una cierta continuidad entre las diferentes juntas de la capilla y un medio para que los sectores que estaban dentro siguiesen estándolo en años venideros ${ }^{28}$. Lo que no se explica en ningún momento es cómo se escogía el cuerpo de electores. Da la impresión de que la selección era más un proceso social que un procedimiento jurídicoinstitucional. Cuando se repasan las nóminas de los electores y se comprueba que en la mayoría de los casos comparecían conocidos hombres del comercio sevillano, se sobrentiende que los presentes tenían claro quiénes tenían algo que decir, sin necesidad de que se estipulase en una ordenanza. Los que votaban eran flamencos o descendientes de tales, por supuesto, y todos eran personas de dinero y prestigio, la mayoría hombres de negocios.

Esta primacía de lo comercial se reflejó también en la determinación del espacio ocupado por la capilla. Como se ha dicho, ésta se hallaba situada en el colegio de Santo Tomás y el hospital, en una casa frontera. Las razones que llevaron a elegir dicho emplazamiento no podían ser más claras:

Era el más apropósito y de mejor y mayores comodidades de quantos auía en la ciudad, porque començando por el sitio estaua junto a todos los lugares donde todos los hombres de negocios suelen acudir más de ordinario y por el consiguiente los de la nación, de suerte que forçosamente yendo y viniendo a sus negocios an de pasar por allí, porque es entre el circuito de los Alcáçares reales, Gradas y la Lonja, iglesia mayor y aduana y Contratación, el río y assí en ygual distancia de todos estos lugares y en la collación de la iglesia mayor, adonde por respeto de las dichas comodidades viuen y hauitan todos o los más de la dicha nación $^{29}$.

26. Ibid., fol. 441.

27. Con carácter previo a la formación de los estatutos no se conservan procesos electivos (los primeros datan de 1616: AHPSe, PNS, leg. 12.717, fol. 486), pero sí hay constancia de juntas de gobierno con una estructura cambiante. Aparentemente, se fueron renovando de forma poco formalizada durante los primeros años, desde 1604 aproximadamente, y sólo en los ejercicios previos a la formación de los estatutos (desde 1613, al menos) se empezó a perfilar con claridad el modelo que quedó fijado en ellos. Véase el apéndice.

28. Estatutos, fols. 441-442.

29. Ibid., fol. 436r. 
En suma, la elección del colegio de Santo Tomás, integrado en la zona portuaria y empresarial de la ciudad, beneficiaba a los hombres de negocios, que solían vivir cerca y frecuentaban las Gradas, el arenal y el río, la Aduana, la Lonja o la Casa de la Contratación ${ }^{30}$. Progresivamente, ese protagonismo mercantil en instituciones religiosas y benéficas terminó traduciéndose en la creación de organismos de carácter más netamente político y comercial.

\section{DE LA CAPILLA AL CONSULADO: LA RIVALIDAD CON LA ESTRUCTURA DEL MONOPOLIO}

La capilla fue el germen del que nació el consulado. El procedimiento fue sencillo en sus aspectos formales, pero resultó difícil consolidarlo. Consistió fundamentalmente en convertir a los mayordomos antiguos de la capilla en cónsules; a partir de determinado momento, los mayordomos nuevos elegidos por la nación dejaron de considerarse mayordomos antiguos después de la siguiente elección y se transformaron en autoridades consulares. Simple en teoría, como puede verse, dado que la novedad que se introducía respetaba un modelo organizativo ya establecido. Sin embargo, la transformación, que no tuvo lugar caprichosamente, se debió a la necesidad que sintieron los flamencos de dotarse de mecanismos de defensa ante las presiones a las que les estaba sometiendo el Consulado de Cargadores a Indias. La construcción de una nueva institución comercial no fue fácil ni estuvo exenta de controversias.

Los años finales del reinado de Felipe II y el reinado de Felipe III aparecen como un escenario en el que el Consulado intentó orientar el modelo monopolístico de la Carrera de Indias hacia su versión más cerrada y exclusivista. Tenía a su disposición una carta maestra para jugar: los asientos del derecho de avería, a través de los cuales se encargó de la financiación de las armadas de la Carrera desde 1591. El compromiso financiero le dio fuerzas; con innegable resignación, la Corona tuvo que reconocerle algunas concesiones a cambio del dinero que pondría todos los años para que la navegación entre España y América siguiese siendo viable. El Consulado aprovechó la coyuntura de diferentes maneras y una de las líneas estratégicas estribó en establecer barreras para la naturalización de extranjeros. Las cédulas sobre la materia de 1592 , 1608 y 1616, así como la comisión en Sevilla del consejero de Indias Francisco de Tejada, tuvieron su origen en las presiones realizadas por el lobby del comercio oficial hispalense $^{31}$.

Para defenderse, los flamencos contaban con una autoridad consular que existía desde el siglo XVI. En 1613, se creía que había habido cónsules flamencos en Sevilla

30. Las relaciones con los dominicos de Santo Tomás fueron largas y muchas veces difíciles, llegando a pleitear en los tribunales. Véanse, por ejemplo, AHPSe, PNS, legs. 12.694, fol. 266; 12.866, fols. 497 y 498; AMS, secc. XI, t. 13, nn. 3 y 5.

31. Collado Villalta, Pedro: «El Consulado de Sevilla: por un mayor protagonismo en la Carrera de Indias: 1591-1608», en Andalucía y América en el siglo XVI, Sevilla, 1983, pp. 275-305; Díaz Blanco: Asi trocaste. 
desde cincuenta años atrás, aunque evidentemente se trata de una ponderación redondeada. Existen referencias muy contadas a estos primeros cónsules flamencos. Se tiene noticia principalmente de un tal Servaes Coomans, que fue cónsul entre finales del XVI y comienzos del XVII. Pese a la parquedad de los datos, bastan para comprobar algo esencial: estos cónsules previos no formaban parte de la comunidad flamenca-alemana de Sevilla, salvo de forma muy tangencial si acaso. Desde luego, no formaban parte de aquella élite dirigente que tanto destacaba a inicios del siglo XVII. Presumiblemente, serían cónsules de designación real directa. Siguiendo el ejemplo del Consulado de Cargadores, al que se enfrentaban, los grandes comerciantes flamencos intentaron construir una estructura consular en la que ellos fuesen los que decidiesen la identidad del titular y, evidentemente, seleccionarlo de entre los suyos. Siempre sería mejor que alguien impuesto desde fuera, mucho más en las tensas circunstancias de entonces. Entendían que, para conseguirlo, podían aprovechar el embrión institucional que estaba surgiendo en la capilla y, efectivamente, fue entonces cuando por primera vez acariciaron la idea: «nos ha parecido cosa muy conveniente que este oficio de cónsul lo usen los dos mayordomos más antiguos que son y adelante fuesen en las dichas casas de obras pías y capilla de las dichas naciones ${ }^{32}$. Aunque el documento intentase forzar una línea de continuidad entre los cónsules tradicionales y los que se estaban intentando crear entonces, la realidad era que se trataba de una idea muy novedosa y no saldría adelante con facilidad ${ }^{33}$.

La refundación seiscentista del consulado flamenco-alemán definió a sus titulares como auténticos representantes de la comunidad, es decir, como autoridades elegidas directamente por los miembros más conspicuos de la misma ${ }^{34}$. En tal sentido, su verdadero punto de arranque se establece en 1615, cuando Felipe III firmó una real cédula mediante la que se aprobaba su establecimiento ${ }^{35}$. Sin duda, no es casual que el duelo con el Consulado alcanzase entonces su punto cenital, con la firma del asiento de avería de 1614 y la llegada a Sevilla el año siguiente del consejero Tejada. Por un poder extendido a fray Enrique Conde, enviado como procurador a Madrid, los flamencos protestaron al Rey que

todos los que de la dicha nación viven y asisten en esta ciudad de Sevilla, así de asiento como de paso a sus negocios, tratos y granjerías de compras y ventas de mercancías y correspondencias, y siendo como somos gente quieta y pacífica y fieles vasallos de su Majestad y católicos cristianos y procurando vivir como procuramos con pacificación sin hacer agravio alguno, somos de ordinario vejados y molestados por jueces, ministros y oficiales reales que cada día de nuevo se mudan y vienen otros que no tienen conocimiento

32. AHPSe, PNS, leg. 10.029, fol. 93; carta, Sevilla, 28 de junio de 1613.

33. GARCía GARCÍA: «La Nación Flamenca», que, significativamente, resalta el apoyo de las autoridades municipales y la oposición del apartado Coomans.

34. Aunque luego, frecuentemente, se buscase la confirmación regia, como una forma de legitimación adicional. Véase, por ejemplo, AHPSe, PNS, legs. 12.911, fol. 145; 12.922, fol. 373; 12.949, fol. 211.

35. CONCHA: «El Almirantazgo de Sevilla», que utiliza una copia de la Biblioteca Nacional; GARCÍA GARCÍA: «La Nación Flamenca», que cita un ejemplar localizado en el Archivo General de Simancas. 
de nuestras personas y de la quietud y buen trato con que vivimos y de lo que procuramos el servicio de Dios nuestro Señor y acrecentamiento de las rentas reales, no defraudando el patrimonio real ni a nadie en cosa alguna ${ }^{36}$.

La cédula consular se explica como un contrapeso de aquel asiento y sus derivaciones políticas. Aunque, igualmente, la escasa ejecución que tuvo puede comprenderse también como una consecuencia de la relajación del conflicto con el Consulado, que tuvo efecto poco después. Ciertamente, la cédula de 1615 no tuvo aplicación inmediata; a pesar de que la complementase otra de 1617, la transformación de los mayordomos antiguos en cónsules no tuvo lugar durante el reinado de Felipe III. La prueba fehaciente se halla en los protocolos de los escribanos públicos. Ni en las actas de los procesos electivos se hace mención a cónsules, ni en escritura alguna comparece ninguno, sino tan sólo los mayordomos ${ }^{37}$. Evidentemente, porque no los había.

La constatación definitiva se deriva de la necesidad de publicar una segunda cédula consular en 1624, que no habría sido necesaria en caso de que la primera hubiese tenido aplicación. No es otra que el célebre documento fundacional del Almirantazgo de los Países Septentrionales, catalogado por José de Abréu y Bertodano como «Ordenanza de Su Magestad, instituyendo, y formando un Consulado, y Compañia con titulo de Almirantazgo de los Comercios de los Países Obedientes de Flandes $\rangle^{38}$. Aquel año, una comitiva real encabezada por Felipe IV y el Conde Duque viajó a Andalucía. Una de las paradas principales tuvo lugar en Sevilla, donde se entablaron negociaciones con diversos colectivos, entre ellos los representantes de la comunidad flamenca. De ahí surgió el Almirantazgo de Sevilla, un intento de trasladar al comercio entre Andalucía y los Países Bajos el sistema de convoyes que había triunfado en la Carrera de Indias y combatir el contrabando ${ }^{39}$. La autoridad consular de la nueva institución queda patente en el tenor del documento: «Es mi voluntad, y tengo por bien, que entre ellos [los flamencos] se forme un Consulado, y Compañia, con titulo de Almirantazgo de los comercios de los Países obedientes de Flandes $\rangle^{40}$. Esta vez la voluntad real se cumplió,

36. AHPSe, PNS, leg. 12.703, fol. 759; poder, Sevilla, abril-mayo de 1614.

37. Véase el apéndice.

38. Abréu y Bertodano, José de: Colección de los tratados de paz, alianza, neutralidad, garantía, protección, tregua, mediación, accesión, reglamento de límites, comercio, navegación, \&c, hechos por los pueblos, reyes y príncipes de España [...] Reynado del s. Rey D. Phelipe IV, parte I, Madrid, 1744, p. 437. Uso el ejemplar de la Biblioteca Universitaria de Sevilla, Fondo Antiguo, A 033(bis)/166.

39. A diferencia del consulado, el Almirantazgo de Sevilla y la Junta del Almirantazgo que lo supervisaba desde Madrid han sido objeto de una amplia atención historiográfica: DomínguEZ OrTIZ, Antonio: «El Almirantazgo de los Países Septentrionales y la política económica de Felipe IV», Hispania, 27 (1947), pp. 272-290 y «Guerra económica y comercio extranjero en el reinado de Felipe IV», Hispania, 89 (1963), pp. 71-110; ConchA: «El Almirantazgo de Sevilla»; DíAz GonzÁLEZ, Francisco J: «La creación de la Real Junta del Almirantazgo (1624-1628)», Espacio, tiempo y forma. Serie IV, Historia Moderna, 12 (1999), pp. 91-128 (así como otros estudios derivados de la Tesis Doctoral del autor); AllozA APARICIO, Ángel: «La Junta del Almirantazgo y la lucha contra el contrabando, 1625-1643», Espacio, tiempo y forma. Serie IV, Historia Moderna, 16 (2003), pp. 217-254.

40. Abréu: Colección de los tratados [...] Felipe IV, parte I, p. 438. 
a diferencia de lo ocurrido en 1615, y una vez más los protocolos notariales se convierten en el medio idóneo para comprobarlo. Demuestran, sin ningún género de duda, que sólo empezaron a nombrarse cónsules a partir de 1625 , no antes ${ }^{41}$.

Por tanto, 1624-25 es la fecha de creación efectiva del consulado de las naciones flamenca y alemana, que cristalizó finalmente como pieza del conglomerado institucional del Almirantazgo de los Países Septentrionales. Fue, por tanto, un fruto de los proyectos reformistas que caracterizaron los inicios del reinado de Felipe IV, uno más de los muchos intentos realizados para relanzar la economía castellana en general y el sector mercantil en particular. Tales aspiraciones se sacrificaron pronto en el altar de la política reputacionista ${ }^{42}$. De hecho, el Almirantazgo fue una creación considerablemente efímera. Casi podría decirse que tiene más importancia como aplicación de un determinado pensamiento económico que como institución con un papel especialmente relevante sobre el desarrollo comercial español. Su final se ha establecido en 1630, apenas cinco o seis años después de la fundación. Sin embargo, este carácter transitorio no fue extensible al consulado de las naciones flamenca y alemana, que sobrevivió durante todo el siglo XVII y llegó al XVIII. La parte duró más que el todo, rigiéndose por las disposiciones de la cédula de 1615 .

La nómina de los mayordomos y cónsules flamencos y alemanes revela el elevado nivel social de las personas que sirvieron el cargo. Todos eran hombres de negocios muy destacados, muchos de ellos bastante conocidos por haberse inmiscuido también en el comercio colonial, obteniendo carta de naturaleza: Nicolás Antonio, Guillén Clout, Francisco de Conique, Andrés Labermayre o Daniel de León, entre otros ${ }^{43}$. Esta coincidencia resulta significativa de varios aspectos importantes. En primer lugar, es una nueva demostración de la inutilidad de fragmentar espacios económicos que, en la realidad, estuvieron profundamente imbricados. Los mismos hombres que protagonizaban el comercio entre Castilla y los Países Bajos se iban integrando también en los mecanismos del negocio colonial (y recuérdese que la naturalización no era, ni mucho menos, la única forma de participar en la Carrera de Indias). Pero, además, arroja luz sobre una dimensión institucional desconocida del incremento de las naturalizaciones de extranjeros durante la privanza de Olivares. Éste se había planteado hasta ahora como un fenómeno social favorecido por el privado contra la opinión del Consulado, la Casa y el Consejo de Indias. Sin embargo, muchos de los mercaderes que se naturalizaron no eran exclusivamente empresarios particulares, sino auténticas

41. Concretamente, el primer protocolo en el que aparecen mencionados los cónsules es en la elección de fray Juan Boquetio, OP, para administrador de la capilla, como sucesor de fray Enrique Conde tras su fallecimiento: AHPSe, PNS, leg. 12.783, fol. 1.121. Los primeros agraciados con la dignidad consular fueron Nicolás Antonio y Juan Cortés, que habían sido electos como mayordomos nuevos para el ejercicio de 1623-24 y en 1625-26 pasaron a la mayordomía antigua, ya consulado. Ver apéndice.

42. Elliott, John H: El conde duque de Olivares. El político en una época de decadencia, Barcelona, 1990.

43. Puede comprobarse muy fácilmente cotejando el apéndice de este trabajo con el listado de extranjeros naturalizados en Domínguez OrTiz: Los extranjeros en la vida española, apéndice 1, pp. 137-164. 
autoridades comerciales, cónsules elegidos por sus propias naciones y favorecidos por el olivarismo.

Así pues, la rivalidad que se encontraba en el origen del consulado flamencoalemán entre 1613 y 1625 tuvo una larga proyección después de esa fecha. El ápice del enfrentamiento entre el Consulado de Cargadores y el consulado flamenco-alemán llegó cuando aquél estuvo en condiciones de frenar e incluso derogar las naturalezas que se habían concedido a través de mecanismos venales. En 1643, cayó Olivares, víctima ilustre de las convulsiones políticas que vivió la Monarquía en la década de 1640. Los consejos del sistema polisinodial fueron invitados a participar de una forma más activa en las decisiones políticas de la corte, incluido el Consejo de Indias. Además, el lugar de Olivares fue ocupado durante un breve tiempo, y hasta cierto punto, por el conde de Castrillo, quien había encabezado la oposición a la concesión masiva de naturalezas en calidad de gobernador del Consejo. Los adversarios madrileños del consulado flamenco-alemán habían pasado a controlar la situación y, fruto de aquella coyuntura, salió a la luz la cédula de extinción de naturalezas venales con fecha de 1645. Muchos comerciantes y cónsules flamencos perdieron entonces su capacidad legal para registrar mercancías en las flotas de Indias ${ }^{44}$.

Evidentemente, el consulado flamenco-alemán no se mantuvo impasible ante semejante desafío. Su respuesta fue valiente: ensayar una transformación radical de su naturaleza institucional, destinada a homologarlo plenamente al Consulado de Cargadores. Se quería dignificar el oficio de cónsul, añadirle un gobierno prioral y dotarle de una jurisdicción judicial más amplia. Lamentablemente, no se conservan testimonios directos de la iniciativa ${ }^{45}$; casi todo lo que se sabe de ella procede de las reacciones que protagonizaron sus adversarios. El Consejo de Indias, la Casa y el Consulado se escandalizaron por la pretensión de aquellos mercaderes extranjeros tanto como por el hecho de que el Consejo de Castilla le hubiese dado un primer visto bueno. Según la voz de los ministros de Indias,

la materia es, Señor, de tanta importancia que obliga al Consejo a repetir a V. Mjd. los muchos inconvenientes que resultarían de dar lugar a que tuviese efecto la introducción de este nuevo consulado, porque ni para el comercio de España ni de las Indias puede ser conveniente que le haya, antes muy perjudicial, porque siendo así que sólo los naturales de estos reinos pueden tratar y contratar en aquéllos y que para la conservación de esta Monarquía y del tráfico y comercio se tuvo por preciso y necesario revocar las naturalezas concedidas a extranjeros, como V. Mjd lo resolvió por consulta de este Consejo, y se va ejecutando, sería superfluo el dicho consulado, y sólo serviría de quitar la jurisdicción al de los naturales y causar continuos daños y competencias entre los dos y un sentimiento general a los comerciantes de estos reinos, viendo que en los negocios y pleitos que tuvie-

44. Díaz Blanco: Así trocaste y «La extinción de las naturalezas venales en la Carrera de Indias (un episodio de la caída del conde duque de Olivares», en Estudios de Historia Moderna en homenaje al profesor Antonio García-Baquero, Sevilla, 2009, pp. 321-335.

45. Con la excepción de los poderes extendidos a procuradores de Madrid, que hablan en términos muy vagos y generales: AHPSe, PNS, legs. 12.893, fol. 273; 12.895, fol. 713; 12.899, fol. 798. 
sen contra los alemanes y flamencos mercaderes habían de ir a litigar ante su consulado, estando en su misma patria ${ }^{46}$.

El centro del problema es claro. El núcleo del comercio español no deseaba compartir privilegios, menos que nunca en aquellos tiempos difíciles.

El expediente de las disputas de 1645 carece de un final administrativo conocido. Es posible que se terminase de resolver en el Consejo de Castilla, pero no se ha hallado ningún papel que lo demuestre. Entonces, ¿cómo finalizó este episodio? Una vez más, los protocolos notariales pueden aportar respuestas. Continuar el análisis de los procesos electivos permite comprobar qué grado de éxito obtuvieron flamencos y alemanes. Si se observa la nómina de los mayordomos y cónsules desde entonces y durante los años $50^{47}$, se apreciará que no hubo cambios relevantes, ni en los procesos de elección ni en la configuración de los equipos de gobierno de la comunidad. Los flamencos y los alemanes habían solicitado un consulado con prior y cónsules, pero jamás llegaron a nombrarse priores de ningún tipo. Sólo siguieron nombrándose cónsules y con las mismas atribuciones que sus predecesores antes de 1645. Nada importante había cambiado, salvo los inevitables relevos generacionales, que traían nombres nuevos a la primera línea, como los de Francisco Paninque, Roberto Jácome y Gutiérrez Mahuis, o el de fray Domingo de Bruselas para administrador ${ }^{48}$. En definitiva, el Consejo de Indias y el Consulado habían logrado consolidar su posición frente a las pretensiones renovadoras del consulado flamenco-alemán y el respaldo que el Consejo de Castilla le había prestado.

Así lo confirma otra relevante iniciativa que flamencos y alemanes emprendieron en 1648. La fecha es sumamente significativa; sin duda, el trasfondo político internacional - con la firma de la Paz de Westfalia, el fin de la Guerra de los Ochenta Años, la definitiva defección holandesa de la Monarquía Hispánica y la permanencia de los Países Bajos católicos- se hallaba presente ejerciendo una influencia notable, aunque nuevamente no pueden perderse de vista los condicionantes más inmediatos que se estaban produciendo dentro del comercio andaluz. Los mercaderes se reunieron en la capilla de San Andrés y acordaron recordar a Felipe IV el «mucho amor con que las dichas naciones en sus provincias sirven y asisten a lo que es de su obligación con la leal caridad que deben a su rey y señor natural», así como las importantes contribu-

46. AGI, IG, leg. 764, s.n., dentro de un expediente donde hay más documentos sobre la materia, redactados por el Consejo, la Casa y el Consulado. Este expediente fue dado a conocer originalmente en DomínGUEZ OrTiz: Los extranjeros en la vida española, p. 112. Puede complementarse, pero sólo de forma parcial, con la correspondencia entre el Consulado y sus procuradores en Madrid: AGI, Consulados, legs. 118 y 119 .

47. Véase el apéndice. En todo caso, Domínguez Ortiz ya se decantaba por una respuesta negativa, aunque contase con una documentación más escasa, procedente de archivos nacionales. Sus argumentos se basaban en la comprobación de que nunca se mencionaba a priores junto a los cónsules y en el nombramiento de jueces conservadores, «que no necesitarían si dispusieran de jurisdicción exenta».

48. Este P. Bruselas fue retratado por el pintor flamenco Cornelio Schut, en un cuadro conservado en el Museo de Bellas Artes de Sevilla. 
ciones económicas que los flamencos realizaban en España. Se habían beneficiado de ellas las armadas y galeones de Indias, así como los rendimientos fiscales de las aduanas de Sevilla, Cádiz, Sanlúcar de Barrameda o Málaga, entre muchas otras. Por tanto, decidieron suplicarle que

se sirva de mandar que las dichas naciones flamenca y alemana que residen en esta ciudad de Sevilla y reinos de Castilla entren y sean comprehendidos en los repartimientos y contribuciones que su Majestad fuere servido de mandar le hagan los naturales de estos reinos y excusarlos y separarlos de dichos repartimientos y contribuciones de donativos, compras de juros, préstamos y otros repartimientos hechos a portugueses, genoveses y franceses y demás extranjeros que residen en esta ciudad y reinos de Castilla.

Para reforzar su petición, se atrevieron a afirmar que «siempre han sido habidos y tenidos por naturales en estos reinos, así por la mucha obediencia de sus provincias a esta Corona como por la mucha comunicación y trato que en estos reinos tienen y nunca han sido considerados por extranjeros ${ }^{49}$. Ciertamente, eso último no era verdad, pero todo debió de parecerles poco en aquel intento de equipararse jurídicamente a los castellanos y distinguirse del resto de extranjeros. A todas luces, aquellos comerciantes estaban tratando una vez más de anular los efectos de la derogación de las naturalezas venales.

Las iniciativas de 1645 y 1648 fracasaron. Después de los éxitos cosechados en tiempos del Conde Duque, podía temerse una etapa más compleja. Pese a ello, parece que algunas aspiraciones de flamencos y alemanes no cayeron completamente en saco roto. Deseaban tener una cierta autonomía judicial y no tardaron mucho en alcanzarla. Se la confirió el juez conservador, una nueva figura institucional de la mayor trascendencia $^{50}$. La concesión inicial se remonta a 1647 , coincidiendo milimétricamente con aquel contexto conflictivo, y aunque la aplicación práctica de este privilegio también se demostró compleja, el tiempo terminó poniendo las cosas en su debido lugar. Estos jueces conservadores no solían ser miembros de la comunidad flamenca-alemana. Eran españoles, pero entendían en los pleitos de la comunidad flamenca y defendían jurídicamente a sus miembros cuando era necesario. Se conoce la identidad de algunos de ellos, que parece vincular el oficio con la Real Audiencia de Grados, como también sucedía con los jueces conservadores de los ingleses ${ }^{51}$.

Si a la obtención de los juzgados de conservación se añade la consolidación y dignificación de la figura de los fletadores, convertidos en vicecónsules con capacidad para auxiliar a los cónsules en las diferentes responsabilidades que éstos no alcanzaban a atender personalmente ${ }^{52}$, se llega a la conclusión de que, a pesar del revés que signi-

49. AHPSe, PNS, leg. 12.911, fols. 26 y 28; carta de poder, Sevilla, 4 de diciembre de 1648.

50. Crespo Solana, Ana: «El juez conservador. ¿Una alternativa al cónsul de la nación?», en AGLietTi, Herrero y Zamora (coords.), Los cónsules de extranjeros, pp. 23-33.

51. GIRARD, Albert: El comercio francés en Sevilla y Cádiz en tiempo de los Habsburgo, Sevilla, 2006 [1932], pp. 124-125; Domínguez OrTIZ: «Documentos sobre los mercaderes flamencos».

52. AHPSe, PNS, legs. 12.875, fol. 511; 12.877, fol. 1.025; 12.888, fol. 691; 12.902, fol. 298; 12.924, fol. $691 ; 12.939$, fol. $463 ; 12.947$, fols. 477 y $1.056 ; 12.967$, fol. $620 ; 12.999$, fol. $12 ; 13.010$, fol. 304 ; 
ficaron la cédula de 1645 y los frustrados intentos para atenuar o esquivar sus efectos, la segunda mitad del reinado de Felipe IV se perfiló finalmente como un período de consolidación para el consulado flamenco-alemán. Aunque faltase la gran figura protectora del conde duque de Olivares en la corte, la institución había sabido encontrar su lugar. Estaba próximo ya su momento de mayor protagonismo dentro de la vida comercial española del siglo XVII.

\section{EL REINADO DE CARLOS II: LA CÚSPIDE DEL CONSULADO FLAMENCO-ALEMÁN}

El reinado de Carlos II puede entenderse como una culminación de la historia institucional del consulado de las naciones flamenca y alemana de Sevilla. Grandes nombres ocuparon la dignidad consular, de no menor entidad que quienes lo hicieron en la primera mitad de siglo. Estos hombres protagonizaron un momento de cambio importante: el consulado flamenco-alemán no fue más un adversario del Consulado de Cargadores y la Casa de la Contratación. Antes al contrario, se convirtió en un aliado para estos sectores más tradicionales del comercio hispalense; en cierto modo, había llegado al fin a convertirse en uno más de ellos. Había terminado de integrarse institucionalmente y había ocupado su propia posición. Una posición importante ${ }^{53}$.

El paso del tiempo no fue lo único que jugó a favor de esta unión. Otras circunstancias la favorecieron. Apareció un enemigo común para todos y una causa por la que luchar juntos. Tomó fuerza entonces un proceso histórico que llevaba el epicentro del comercio colonial de Sevilla a Cádiz ${ }^{54}$. Varios factores confluían en él, políticos, económicos, sociales o náuticos, pero también fiscales. Los comerciantes instalados en Sevilla veían con preocupación las diferencias aduaneras con Cádiz que habían introducido Francisco Báez Eminente, el experimentado hombre de negocios portugués que había arrendado los almojarifazgos, y Luis de Vivar, arrendador de las alcabalas de la

53. Dígase esto sin olvidar las inevitables dificultades económicas del hospital, de las que da cuenta ORTIZ DE ZúÑIGA: Anales, IV, p. 139.

54. Sin pretensión de exhaustividad, GIRARD, Albert: La rivalidad comercial y marítima entre Sevilla y Cádiz hasta finales del siglo XVIII, Sevilla, 2006 [1932]; Collado Villalta, Pedro: «En torno a los orígenes del monopolio comercial gaditano: mercaderes extranjeros y cambio económico del área sevillana a la Bahía de Cádiz en la segunda mitad del siglo XVII», en Actas del II Coloquio de Historia de Andalucía. Andalucía Moderna, Córdoba, 1983, I, pp. 603-616; Heredia Herrera, Antonia: «Las elecciones en el Consulado de Cargadores a Indias: nuevas perspectivas sobre la rivalidad entre Sevilla y Cádiz», en Primeras Jornadas de Andalucía y América, Huelva, 1981, I, pp. 167-180; Ravina MarTín, Manuel: El pleito Cádiz-Sevilla por la Casa de contratación. Memorial de Francisco Manuel Herrera, 1726, Cádiz, 1984; Bustos Rodríguez, Manuel: «De Sevilla a Cádiz: hacia el cambio de funcionalidad en el seno del monpolio andaluz con América (1600-1650)», en Martín, Javier, VelázQuez, Fernando y Bustamante, Joaquín (eds.): Estudios de la Universidad de Cádiz ofrecidos a la memoria del Profesor Braulio Justel Calabozo, Cádiz, 1998, pp. 487-498; GarcíA-Mauriño Mundi, Margarita: La pugna entre el Consulado de Cádiz y los jenizaros por las exportaciones a Indias, Sevilla, 1999; Oliva Melgar, José María: El monopolio de Indias en el siglo XVII y la economía andaluza. La oportunidad que nunca existió, Huelva, 2004; Díaz Blanco: Asi trocaste, cap. 5. 
ciudad $^{55}$. En su opinión, las tasas más bajas estaban beneficiando a Cádiz y dañaban la vitalidad de Sevilla. La idea era común para todos. Francisco Báez Eminente perjudicaba a todos. El nuevo comercio de Cádiz lastraba a todos. Todos estuvieron dispuestos a enfrentarse al curso de los acontecimientos.

La nómina de las personas que ocuparon la dignidad consular desde 1665 en adelante contiene apellidos muy importantes en el comercio andaluz del momento: Pluyms, Maestre, Mahuis, Lepin, Clarebout o Del Campo/Malcampo, entre otros varios. Sus representantes más encumbrados tendieron a estabilizarse dentro de la dignidad consular y a repetir varias veces en el cargo. Por citar algunos ejemplos: Gaspar Pluyms y Alberto Ancquelman, que habían sido mayordomos entre 1663 y 1664, ocuparon el consulado ininterrumpidamente de 1665 a 1671. Enrique Lepin, mayordomo en 1675-76, fue cónsul desde 1678 hasta 1683 y luego volvió a serlo otra vez entre 1700 y $1703^{56}$. Además, detrás de los individuos estaban las familias, ya que muchos de estos hombres estaban emparentados entre sí. De tal modo, hubo dinastías que controlaron los resortes del consulado durante años y años ${ }^{57}$.

Estos procesos de estabilización en el cargo no habían tenido precedentes durante la primera mitad del XVII, aunque coincidían en el tiempo con lo que estaba sucediendo en otras instituciones del entorno, pues el Consulado de Cargadores también experimentó esas mismas tendencias de consolidación ${ }^{58}$. Es probable que el fenómeno tenga mucho que ver con el empobrecimiento de las comunidades mercantiles sevillanas a fines del siglo XVII. Las grandes personalidades habrían tenido mayores posibilidades de enrocarse en el poder en un marco menos vitalista y competitivo ${ }^{59}$. De cualquier modo, los ejemplos más notables de perpetuación coinciden con la implicación del consulado flamenco-alemán en las disputas políticas frente a Francisco Báez Eminente y las pretensiones comerciales de Cádiz. Son los casos de Gaspar Pluyms, Alberto Ancquelman y Enrique Lepin, que fueron efectivamente los protagonistas de los momentos álgidos de este conflicto, en 1666 y 1680. Ambas fechas enmarcan de forma aproximativa el momento a partir del cual se produjo el giro en las relaciones entre el consulado flamenco-alemán y las demás instituciones del comercio sevillano.

55. SAnz Ayán, Carmen: Los banqueros de Carlos II, Valladolid, 1988, pp. 346-351 y 422; Pulido Bueno, Ildefonso: Almojarifazgos y comercio exterior en Andalucía durante la época mercantilista, 1526-1740, Huelva, 1993, pp. 131-135.

56. Ver apéndice.

57. Es lo que sucedió, por ejemplo, con la red familiar que unía a los Maestre, los Mahuis y los Príncipe. En la actualidad, se encuentra en preparación una investigación sociológica sobre los cónsules del XVII que ahondará en este tipo de cuestiones, que sólo puede apuntarse ahora.

58. Heredia Herrera, Antonia: «Los dirigentes oficiales del Consulado de Cargadores a Indias», en Andalucía y América en el siglo XVII, Huelva, 1985, pp. 217-236.

59. En cambio, es completamente descartable que se deba a los procedimientos de venta o beneficio de oficios que tanto prosperaron entonces en la Casa de la Contratación: ANDúJAR CASTILlo, Francisco: «La Casa de Contratación de Sevilla y la venalidad de los cargos (1634-1717)», en GAMERo, Mercedes y NúÑEZ, Francisco (coords.), Entre lo real y lo imaginario, Sevilla-Huelva, 2014, pp. 47-73. 
Hacia 1666, Gaspar Pluyms y Alberto Ancquelman se unieron al Consulado de Cargadores y los gremios de la ciudad para denunciar a Eminente. Todos actuaron de consuno, gran novedad. El Cabildo escribió al Consejo de Castilla, el Consulado se dirigió al Consejo de Indias y el consulado flamenco-alemán trató con el Consejo de Hacienda, ante quien se querellaron contra el portugués ${ }^{60}$. Entre los papeles que pusieron a disposición de los ministros, destaca un impreso en el que explican cómo las naciones extranjeras tenían «dos géneros de Comercio» en España, el que suministraba mercancías al reino y el que se destinaba a la reexportación a las Indias. Según Pluyms y Ancquelman, «estos dos Comercios estuvieron juntos en Sevilla desde la Antigüedad, hasta el año de 1635». Fueron tiempos de enorme opulencia, truncada por el estallido de la guerra contra Francia, que desestabilizó el comercio que se había mantenido hasta entonces con franceses y holandeses. Éstos, para sortear la situación, comenzaron a actuar de contrabando en la bahía de Cádiz y pronto les imitaron las otras naciones. La buena administración de los almojarifazgos, efectuada por ministros como Jerónimo de San Vítores o el conde de Villaumbrosa, permitió paliar los efectos de una situación tan irregular. Sin embargo, los arrendadores, menos preocupados por el bien común, la habían agravado, introduciendo los beneficios fiscales de que disfrutaba Cádiz. Primero lo hizo Simón Rodríguez Bueno y, desde 1663, Báez Eminente. La catástrofe general tenía nombres y apellidos ${ }^{61}$.

El frente sevillano tuvo un éxito notable en Madrid. Obtuvo como resultado la publicación de la real cédula de 6 de septiembre de 1666, por la que se eliminaba la tabla de Indias y el tercio de frutos, y se establecía la equidad aduanera entre Sevilla y Cádiz ${ }^{62}$. Incluso Báez Eminente fue alejado transitoriamente de los almojarifazgos, aunque poco después consiguió arrendarlos de nuevo. El éxito de la causa significó también un éxito personal de Pluyms y Ancquelman dentro de la comunidad flamencaalemana. Ambos eran ya grandes personalidades, ricos comerciantes que podían presumir de magníficas relaciones sociales, y el triunfo sobre Eminente aumentó aun más ese prestigio. Un documento colectivo de 1670 alaba la «solicitud, cuidado, entereza y justicia» que emplearon en pleitear exitosamente contra los arrendadores de rentas y reconoce la conveniencia de compensarles por el dinero que habían gastado en los juicios ${ }^{63}$.

60. AGI, IG, leg. 633, s.n; «Decretos, consultas y otros documentos sobre que el Juzgado de Indias y Aduana de Cádiz se pase a Sevilla y que en el río se carguen las flotas, observándose la entrada de éstas y galeones en Sanlúcar», expediente con interesantísima documentación fechada entre 1637 y 1667.

61. AMS, secc. XI, t. 29, n. 14; Respvesta de Gaspar Plvyms, y Alberto Ancqvelman, consvles por el rey nvestro señor, de las Naciones Flamenca, y Alemana, que residen en la Ciudad de Sevilla, Sevilla, 8 de junio de 1666. En el mismo tomo hay más documentación sobre la materia, que fue puesta en valor por GIRARD: La rivalidad, pp. 104-105. Hay una edición digital de este impreso en: http://ddd.uab.cat/pub/ pragmatiques/pragmatiques_89.pdf [consultado en 31 de enero de 2015].

62. AGI, Contratación, leg. 5.039.

63. AHPSe, PNS, leg. 12.987, fol. 698; ratificación, Sevilla, 18 de marzo de 1670. 
Sin embargo, el conflicto contra Cádiz no estaba ni mucho menos cerrado. En 1679, Carlos II reinstitucionalizó el comercio gaditano, devolviéndole su tabla de Indias y el tercio de frutos ${ }^{64}$. Inmediatamente cundió la preocupación en Sevilla, cuyas élites comerciales se movilizaron frente a este nuevo avance gaditano. El consulado flamenco-alemán volvió a empeñarse en la causa y, una vez más, lo hizo junto al Consulado y la Casa. Se diría que esta vez incluso asumió mayores dosis de protagonismo. Al menos, la implicación del cónsul Enrique Lepin parece haber sido más intensa que la de Pluyms y Ancquelman, de modo que pudo presentarse en la corte no sólo como cónsul, sino también como «diputado general de las naciones flamenca, alemana, inglesa, francesa e italiana» de Sevilla ${ }^{65}$. Lepin era alemán, natural de Hamburgo. Se instaló inicialmente en Cádiz, pero, al entroncar por vía matrimonial con la poderosa dinastía de los León-Paninque, se trasladó a Sevilla, donde prosperó como hombre de negocios hasta su fallecimiento en $1709^{66}$.

$\mathrm{Su}$ actuación tuvo origen en una junta general de la nación flamenca celebrada en 1680. Todos los presentes, comerciantes flamencos y alemanes, repitieron una cantinela muy conocida, que se había escuchado con frecuencia en ocasiones anteriores: la desigualdad tributaria que había introducido Báez Eminente provocaba estragos en la economía comercial de Sevilla y era justo terminar con ella. Lepin recibió de sus compatriotas el encargo de denunciarlo ante las autoridades de la Monarquía ${ }^{67}$. El hamburgués acudió a Madrid, negoció en la corte con los ministros de su Majestad y se convirtió en la avanzadilla de la facción sevillana. El momento señala el punto cenital en el liderazgo político ejercido por el consulado flamenco-alemán. Ha quedado para la posteridad un memorial impreso de gran calidad literaria y máximo interés histórico, en el que Lepin desarrolla una explicación a largo plazo de la evolución del comercio sevillano. Consensuada con las comunidades mercantiles a las que representaba, se parece a la de Pluyms y Ancquelman, aunque no es igual. Según Lepin, Sevilla había vivido en la opulencia gracias al descubrimiento de América, pero su prosperidad había ido desapareciendo desde 1632, a causa del arrendamiento de los almojarifazgos a financieros portugueses como Marcos Fernández Monsanto, Simón Rodríguez Bueno

64. GIRARD: La rivalidad.

65. AGI, IG, leg. 787, s.n.; el Consulado de Cargadores a Carlos II, Sevilla, 20 de agosto de 1680. E1 documento afirma que todas esas naciones «nombraron por su diputado general a don Enrique Lepin, quien con poderes bastantes pasó a la corte»; lamentablemente, no se ha podido hallar la carta de poder o nombramiento entre los protocolos sevillanos, excepto la documentación citada a continuación, que se limita a decisiones internas de la comunidad flamenca-alemana, aunque el escribano lo catalogase como poder de los «cónsules de las naciones» a Lepin: AHPSe, PNS, leg. 18.559, abecedario segundo de 1680 , letra L.

66. Díaz Blanco, José Manuel: «Un mercader alemán en Andalucía: Enrique Lepin, entre Sevilla y Cádiz (siglos XVII-XVIII)», en prensa.

67. AHPSe, PNS, leg. 13.016, fol. 602; carta de poder, Sevilla, 15 de junio de 1680. 
y, cómo no, Francisco Báez Eminente, calificado como el peor de todos y contra quien había que luchar ${ }^{68}$.

La negociación de Lepin, avalada por el Consulado y la Casa de la Contratación, fue aplaudida en Madrid. El Consejo de Indias en pleno le dio su respaldo y el monarca no tuvo más remedio que declararse favorable a la equidad fiscal en Andalucía ${ }^{69}$. Evidentemente, los años siguientes fueron difíciles y Cádiz, que no volvió a verse privado de sus instituciones mercantiles, siguió acaparando cuotas crecientes de comercio. En cualquier caso, eso no es especialmente relevante para el presente análisis: no se trata de calibrar aquí la aplicación efectiva de los propósitos de 1680, que se enfrentaban a un curso de acontecimientos difícil de detener. Lo que interesa es constatar cómo el consulado flamenco-alemán se había situado al frente de la embajada sevillana en la corte en un momento crucial como aquél. La institución que había surgido entre tantas dificultades a comienzos del siglo XVII, se había consolidado trabajosamente en las décadas centrales y llegaba, al fin, a su cenit en el reinado de Carlos II.

68. AGI, IG, leg. 787, s.n.; «Memorial que dio al Rey nuestro señor Enrique Lepin, diputado general de las naciones que residen y comercian en la ciudad de Sevilla», s.f. [1680]. Citado en CárCeles De GeA, Beatriz: Derecho y comercio en la Corona de Castilla en el siglo XVII, Madrid, 2013.

69. AGI, IG, leg. 787, s.n.; consulta del Consejo de Indias, Madrid, 5 de octubre de 1680. 


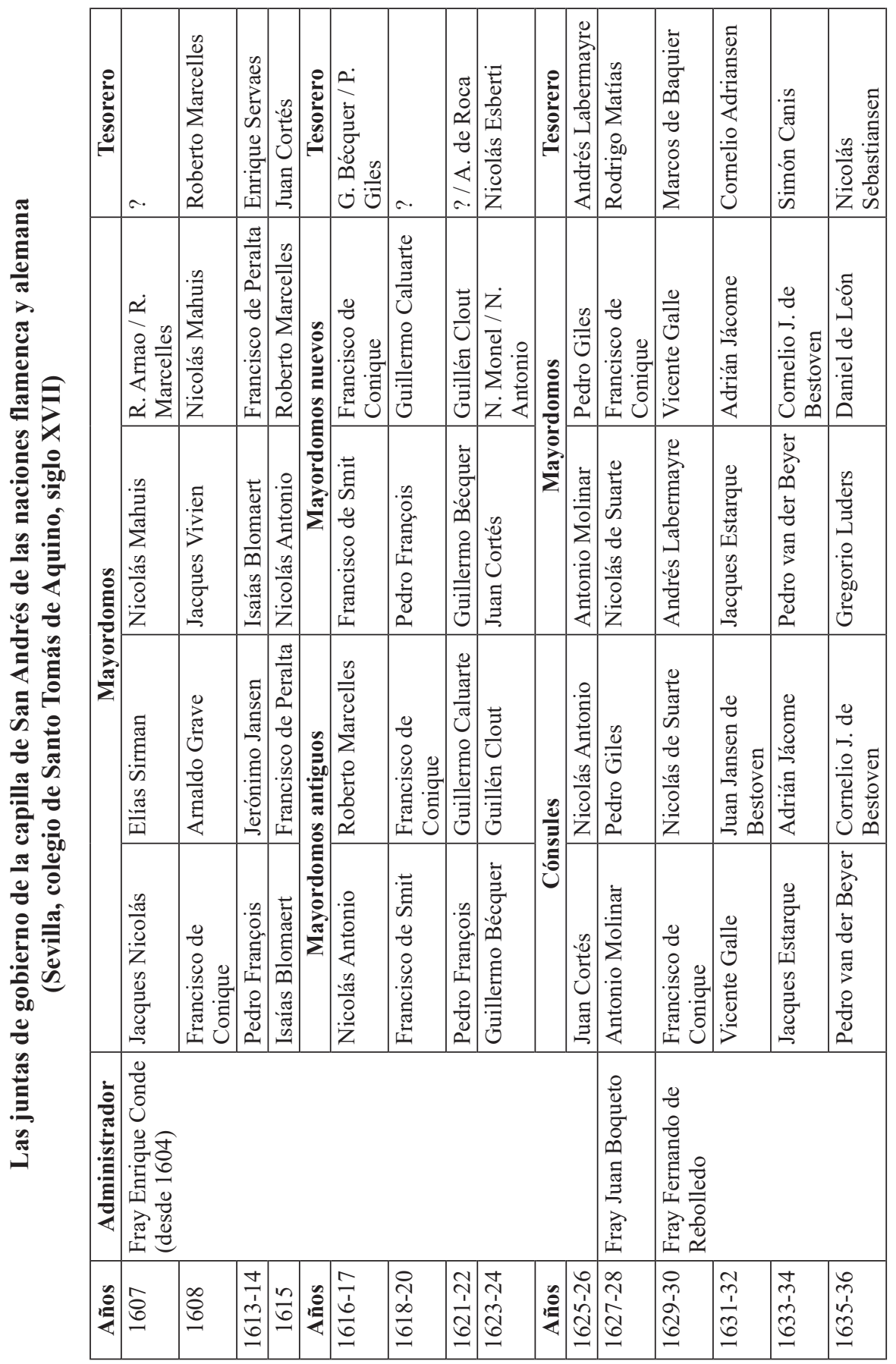




\begin{tabular}{|c|c|c|c|c|c|c|c|c|c|c|c|c|c|c|c|}
\hline 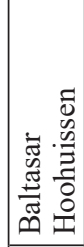 & 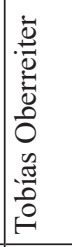 & 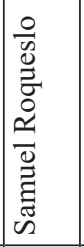 & 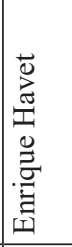 & 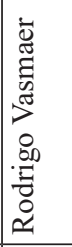 & 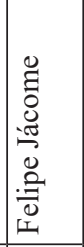 & 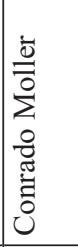 & 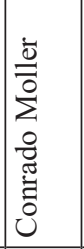 & 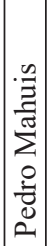 & 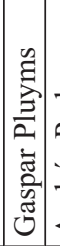 & 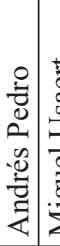 & 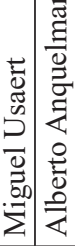 & 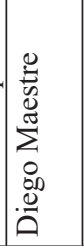 & 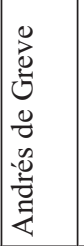 & 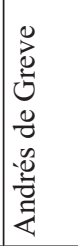 & 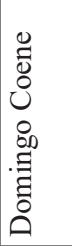 \\
\hline 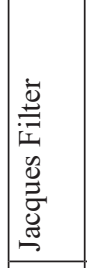 & 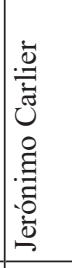 & 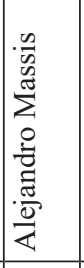 & 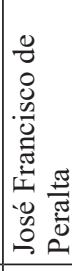 & 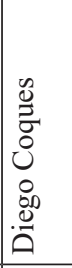 & 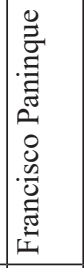 & 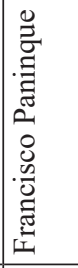 & 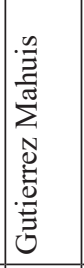 & 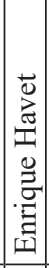 & 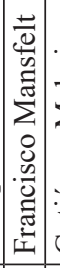 & 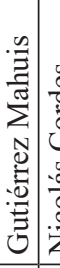 & 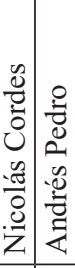 & 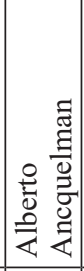 & 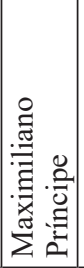 & 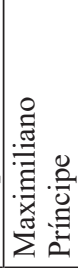 & 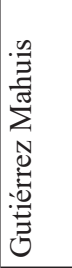 \\
\hline 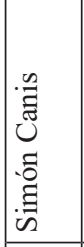 & 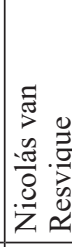 & 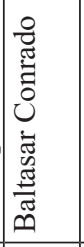 & 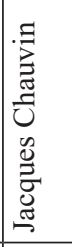 & 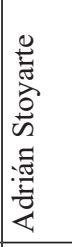 & 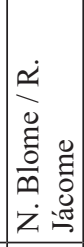 & 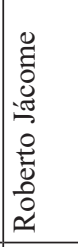 & 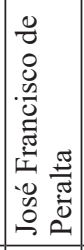 & 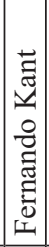 & $\mid \begin{array}{l}4 \\
0 \\
0 \\
0 \\
0 \\
0 \\
0 \\
0 \\
0 \\
\Xi \\
0 \\
0\end{array}$ & 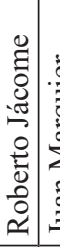 & 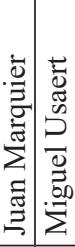 & 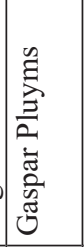 & 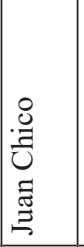 & 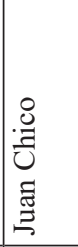 & 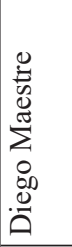 \\
\hline 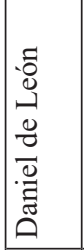 & 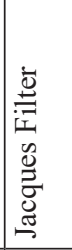 & 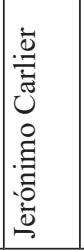 & 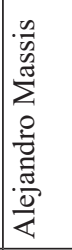 & 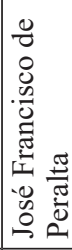 & 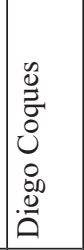 & 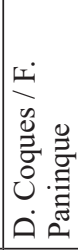 & 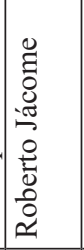 & 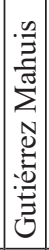 & 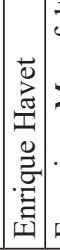 & 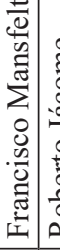 & 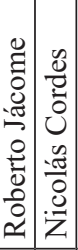 & 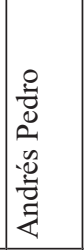 & 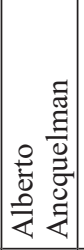 & 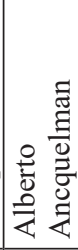 & 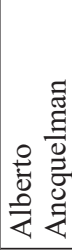 \\
\hline 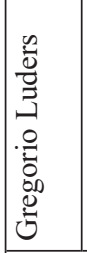 & 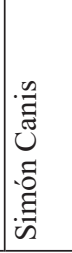 & 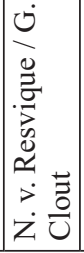 & 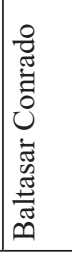 & 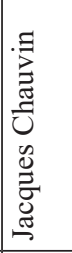 & 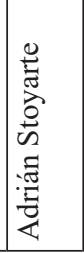 & 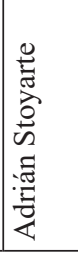 & 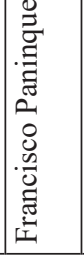 & 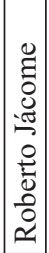 & 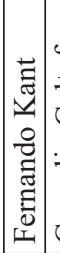 & $\begin{array}{l}4 \\
0 \\
0 \\
0 \\
0 \\
0 \\
0 \\
0 \\
0 \\
0 \\
0 \\
0\end{array}$ & 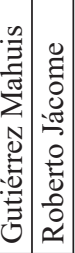 & 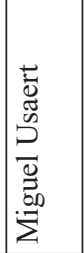 & 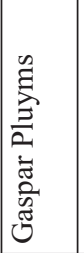 & 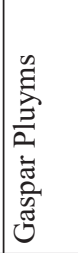 & 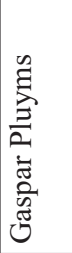 \\
\hline & & & & 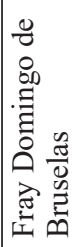 & & & & & & & & & 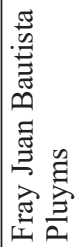 & & \\
\hline 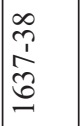 & 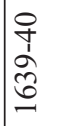 & $\underset{\stackrel{Y}{I}}{\stackrel{f}{J}}$ & 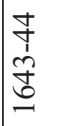 & 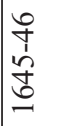 & 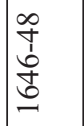 & 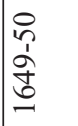 & $\frac{n}{12}$ & $\mid \begin{array}{l}0 \\
n \\
1 \\
n \\
\tilde{n} \\
-1\end{array}$ & $\mid \begin{array}{l}0 \\
n \\
n \\
n \\
0 \\
-1\end{array}$ & \begin{tabular}{l}
$\infty$ \\
$n$ \\
$i$ \\
$n$ \\
0 \\
\hdashline
\end{tabular} & 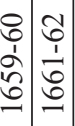 & $\begin{array}{l}0 \\
0 \\
1 \\
0 \\
0 \\
0 \\
-1\end{array}$ & $\begin{array}{l}0 \\
0 \\
1 \\
1 \\
0 \\
0 \\
-1\end{array}$ & $\begin{array}{l}0 \\
1 \\
1 \\
0 \\
0\end{array}$ & $\begin{array}{l}\overline{1} \\
\hat{\sigma} \\
\hat{\sigma} \\
-1\end{array}$ \\
\hline
\end{tabular}




\begin{tabular}{|c|c|c|c|c|c|c|c|c|c|c|c|c|c|}
\hline 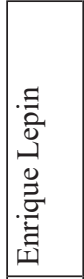 & 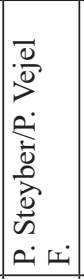 & 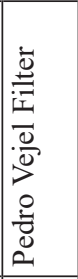 & 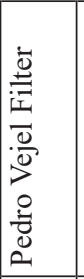 & 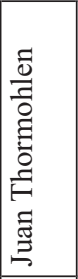 & 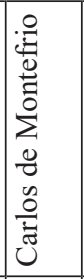 & 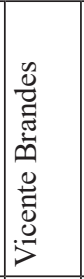 & 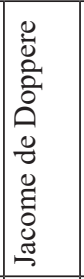 & 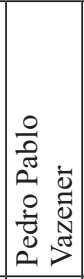 & 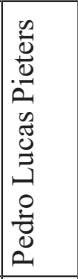 & 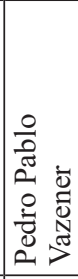 & 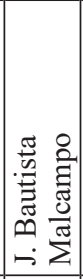 & 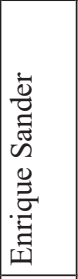 & 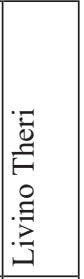 \\
\hline 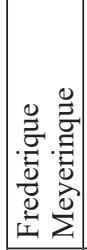 & 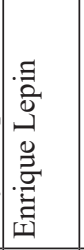 & 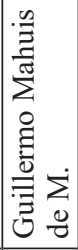 & 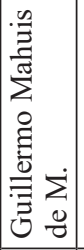 & 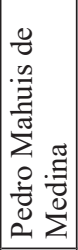 & 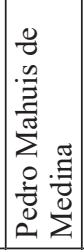 & 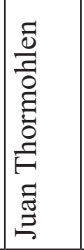 & 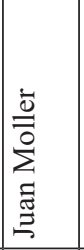 & 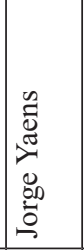 & 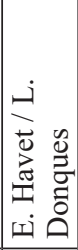 & 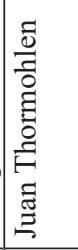 & 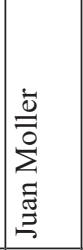 & 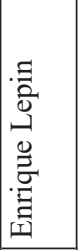 & 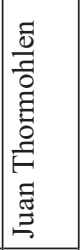 \\
\hline 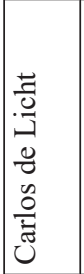 & 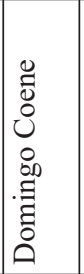 & 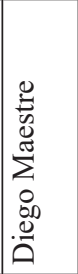 & 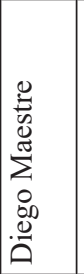 & 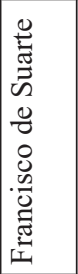 & 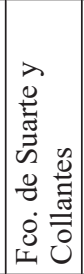 & 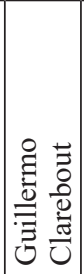 & 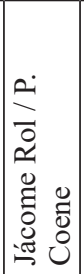 & 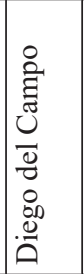 & 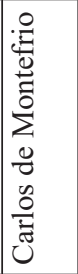 & 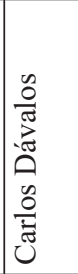 & $\begin{array}{l}\frac{0}{0} \\
\frac{\pi}{0} \\
2 \\
0 \\
0 \\
0 \\
0\end{array}$ & 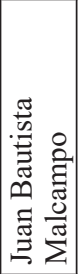 & 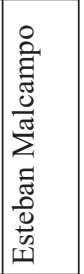 \\
\hline 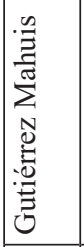 & 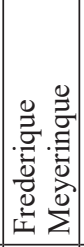 & 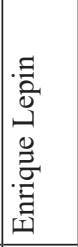 & 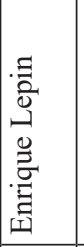 & 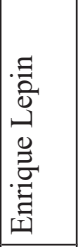 & 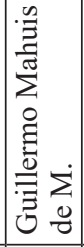 & 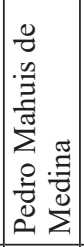 & 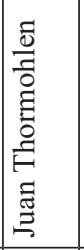 & 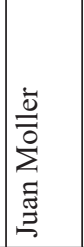 & 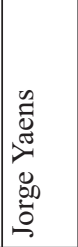 & 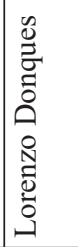 & 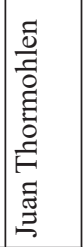 & 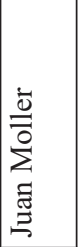 & 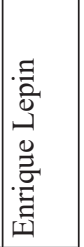 \\
\hline 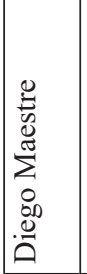 & 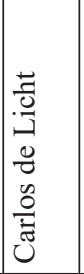 & 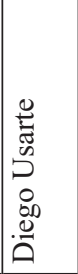 & 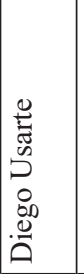 & 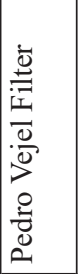 & 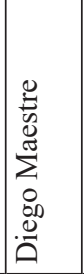 & 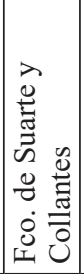 & 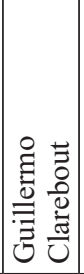 & $\begin{array}{l}0 \\
\tilde{D} \\
0 \\
0 \\
0 \\
\vdots \\
0 \\
0\end{array}$ & 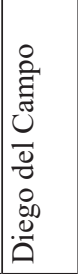 & 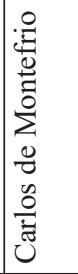 & 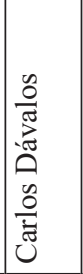 & \begin{tabular}{|l}
0 \\
$\frac{0}{t}$ \\
$\frac{\pi}{0}$ \\
0 \\
0 \\
0 \\
0 \\
0 \\
0
\end{tabular} & 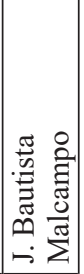 \\
\hline & & & 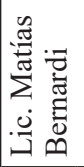 & & & & & & a. & & & & \\
\hline $\begin{array}{l}\underset{ \pm}{ホ} \\
\underset{\sigma}{\sigma} \\
-1\end{array}$ & $\begin{array}{l}\hat{i} \\
\frac{1}{2} \\
6 \\
-0\end{array}$ & $\begin{array}{l}0 \\
\infty \\
1 \\
\infty \\
6 \\
0 \\
-1\end{array}$ & $\underset{\infty}{\infty}$ & 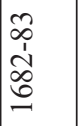 & $\begin{array}{l}n \\
\infty \\
1 \\
1 \\
\infty \\
0 \\
0 \\
-1\end{array}$ & $\begin{array}{l}1 \\
\infty \\
1 \\
0 \\
0 \\
0\end{array}$ & $\begin{array}{l}2 \\
\infty \\
1 \\
\infty \\
\infty \\
0 \\
-1\end{array}$ & $\begin{array}{l}\bar{a} \\
\text { ò } \\
\text { ô } \\
-1\end{array}$ & 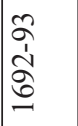 & 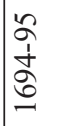 & $\begin{array}{l}\hat{a} \\
\hat{b} \\
\text { ò }\end{array}$ & $\begin{array}{l}2 \\
\hat{a} \\
0 \\
0 \\
-\end{array}$ & 立 \\
\hline
\end{tabular}

